\title{
Factors associated with use of injectables, long-acting and permanent contraceptive methods (iLAPMs) among married women in Zambia: analysis of demographic and health surveys, 1992-2014
}

Pauline Bakibinga ${ }^{1 *}$, Dennis Matanda², Lyagamula Kisia ${ }^{1}$ and Namuunda Mutombo ${ }^{3}$

\begin{abstract}
Background: Zambia, with its women having five children on average, is one of the countries in sub-Saharan African with the highest fertility rates. As the country works on expanding its reproductive health programs, this analysis sought to understand factors behind the current utilisation of injectable, long acting and permanent methods (iLAPMs) of contraception.

Methods: Cross-sectional secondary data drawn from the Zambia Demographic and Health Surveys (ZDHS) were used. This included married women aged 15-49 for the years $1992(n=620), 1996(n=1176), 2001 / 02(n=1483)$, $2007(n=1665)$ and 2013/14 ( $n=4394)$. Frequencies, cross-tabulations and logistic regression were used to analyse levels and differentials in use of iLAPMs.

Results: Except for the variables "religion" and "region", the rest of the independent variables show significance on the use of iLAPMs, at varying levels. "Desire for children" is the strongest predictor of use of iLAPMs as it was significant at all the five data points. This is followed by "age", although it was not significant in 2007. "Education of the woman and partner" and "number of living children" were also significant, but only for two out of the five data collection points. "Ethnicity", "type of residence", "heard about FP in last 12 months", and "main decision maker on woman's health" were only significant for one out of the five data points.

Conclusion: This study has established that women's desire for children is the main factor influencing use of iLAPMs in Zambia. Women who still want to have children are less likely to use iLAPMs even though the odds of using these methods among these women increased between 1992 and 2014. This indicates that most of this increase is due to the desire by these women to space births rather than stop having children. The 2013/2014 data also suggest an increase in access to iLAPMs among the less privileged women i.e. those in rural areas and those with low levels of education. This trend appears to have stemmed from the scaling up of family planning programmes to cover rural communities. Greater effort should be invested into family planning programs that reach all categories of women.
\end{abstract}

Keywords: Modern contraception, Family planning, iLAPMs, Zambia

\footnotetext{
* Correspondence: paulabak80@gmail.com

${ }^{1}$ African Population \& Health Research Center, P.O.Box 10787, Nairobi 00100,

Kenya

Full list of author information is available at the end of the article
}

(c) The Author(s). 2019 Open Access This article is distributed under the terms of the Creative Commons Attribution 4.0 International License (http://creativecommons.org/licenses/by/4.0/), which permits unrestricted use, distribution, and reproduction in any medium, provided you give appropriate credit to the original author(s) and the source, provide a link to the Creative Commons license, and indicate if changes were made. The Creative Commons Public Domain Dedication waiver (http://creativecommons.org/publicdomain/zero/1.0/) applies to the data made available in this article, unless otherwise stated. 


\section{Plain English summary}

Sub-Saharan Africa's (SAA) population grows rapidly each year. Many people desiring to limit childbirths still have an unmet need for family planning. Zambia is one of the countries in SAA with the highest number of children being born to one woman. On average, Zambian women have five children. As the country works on expanding its reproductive health programs, the purpose of this analysis was to understand factors behind the current utilisation of injectable, long acting and permanent methods (iLAPMs) of contraception.

We analysed data from the Zambia Demographic and Health Surveys (ZDHS). This included married women aged 15-49 for the years 1992, 1996, 2001/02, and 2013/14. The data wre analysed using different statistical analysis.

We found a strong link between the use of iLAPMs of contraception and the following factors: both maternal and partner's educational achievement, maternal age, number of living children in a household, woman's place of residence (urban/rural), and exposure to family planning messages through media.

Other results showed that:

- In 1996 and 2013/14, women with a primary education or no education were less likely to use iLAPMs of contraception compared to women with a secondary education or and/or a higher education.

- In 1992, 1996 and 2001/2, younger women within the ages of 15-24 years and 25-34 years, were less likely to use iLAPMs of contraception compared to women aged 35 years and older. However, in 2013 and 2014, younger women aged 15-24 were three times more likely to use iLAPMs contraception methods compared to older women. While, women aged 25-34 two times more likely.

- In 2001/2, 2007 and 20,013/4, women with 3-4 children were less likely to use iLAPMs of contraception compared to those with five or more children.

- In the 2001/2 survey, women in urban areas were twice more likely to use iLAPMs of contraception compared to residents of rural areas.

\section{Introduction}

In 2018, the world population reached 7.6 billion people and is expected to increase by $33 \%$ to nearly 10 billion people, in 2050 [1]. Nowhere in the world is a population explosion a challenge as in sub-Saharan Africa (SSA). At approximately 3\% per annum, the annual population growth rate in SSA is expected to result in 2.7 billion people by 2050 . SAA together with India and China, will contribute the largest proportion to the world's population by 2060 . The decline in fertility has been substantially slower in Africa as compared to other regions like Asia, Latin America and the Caribbean at comparable stages of fertility transition [2, 3]. Total fertility rates in countries such as Niger (7.2), Democratic Republic of Congo (6.1), Burundi (5.7), Uganda (5.6), Nigeria (5.5), Zambia (5.0) and Tanzania (5.0) are some of the highest is SAA [4].

The current rapid annual population growth rate is largely a result of a persistently high unmet need for family planning in addition to advances in healthcare in the past two centuries that have presented the world with considerable gains in life expectancy. Nearly 200 million women (15-49 years) in developing regions who want to avoid pregnancy are not using a modern contraceptive method, with SAA having the highest proportion of women with unmet needs for modern contraception (21\%) [5]. In developing regions, women with unmet need and using no method account for 84 and $74 \%$ respectively of all unintended pregnancies [5]. Twothirds of African countries have a level of unmet needs that exceeds 25\%, with East and Southern Africa having a $45 \%$ unmet need [6,7]. Although limiting births is a major factor in driving the fertility transition and has a greater impact on fertility rates than spacing births, research has shown that only $14 \%$ of women wanted to limit child bearing compared to $25 \%$ who wanted to space births [8]. Among married women, the demand to limit was nearly equal to that for spacing [8]. Consequently, 24\% of married women in Africa have an unmet need for contraception [6].

The modern contraceptive prevalence and met need has increased in SAA due to changes in behaviour consistent with ongoing family planning promotions and programmes [9]. However, none use of modern contraception remains predominant in many SAA countries despite it being more effective than traditional methods in preventing unwanted pregnancies. In East and Southern Africa alone, modern use among married women is at $36 \%$ and no method at 59\% [7]. Increasing access to effective family planning methods is important because in the first year of contraceptive use, failure rates are almost zero for permanent methods, below $1.8 \%$ for long acting methods, $4.6 \%$ for short-term methods, and up to $22 \%$ for traditional methods [10]. As a result, long-acting and permanent methods (LAPMs) were found to significantly reduce the number of unintended births and induced abortions (which correlate with low access to modern contraception) if used in place of less effective methods $[10,11]$. It is therefore crystal clear that the use of LAPMs offers the best strategy for countries with high fertility rates and unmet need for contraceptives [12].

Although the Zambian contraceptive prevalence rate has over the years increased from 15\% (1992) to $49 \%$ (2013-14), and the use of modern contraceptives risen from 9 to $45 \%$, over the same period, this growth has 
not kept pace with the annual population growth rate of $3 \%$. On average, a woman in Zambia produces 5 children, a reduction from a total fertility rate of 6.5 reported in 1992, however, Zambian women are still having 0.8 more children than their ideal number [13]. The number of children was found to be a positively associated determinant for a woman's total unmet need [14]. According to Pasha et al. (2015), 22\% of Zambian women seeking to prevent birth and 26\% wanting to delay pregnancy had an unmet need [15]. Among married women, $45 \%$ were using a modern method, but $21 \%$ have an unmet need for family planning services [13]. Those with access were $19 \%$ less likely to seek family planning services with their husbands [16]. Zambia's population is currently estimated at 16.6 million people and the proportion of women who want to limit child birth has only increased by $1 \%$ since 2007 [13]. Given the high unmet need noted above, this untamed growth has serious economic, social and health consequences as the pressure on the limited resources hinders effective delivery of vital services.

A recent analysis of the trends in modern contraceptive methods and factors related to current use in Southern Africa, including Zambia, showed that use had increased over the years and that the gap between urban and rural dwelling women had narrowed (35\% vs $31 \%$ ) [17]. Employment status, education level and residence were strongly associated with current use of modern contraceptives. It is important to note that not all modern contraceptive methods provide protection against unplanned and/or unwanted pregnancies.

Long-acting and permanent methods (LAPMs) are the most effective modern contraceptive methods. Their value is appreciated in their ability to reduce the incidence of unintended pregnancy, as such averting the likelihood of abortion and its complications and reducing the risk of pregnancy related deaths. In spite of their documented value, they are the least utilised methods in SSA and globally $[18,19]$. The common reasons for using longacting reversible contraception (LARC) include longer protection, better child spacing and effectiveness. There are several factors contributing to the low use of long acting and permanent methods of contraception, including method related reasons, inadequate knowledge, opposition to use, and lack of trained health providers.. For example, mothers with high knowledge of LAPMs are eight times more likely to use them than those who had no knowledge [20]. Moreover, Mutombo and Bakibinga, found that Zambian women who made joint decisions on contraceptives are significantly more likely to use iLAPMs than those who did not involve their husbands [21].

Barrier and short-term methods have high discontinuation and failure rates. In Zambia, 7\% contraceptive users discontinued using a modern method within 12 months of starting due to side effects and/or health concerns. Women, in different studies, have also mentioned that one of the main reasons for none use is fear of side effects and/or health concerns $[6,8,14]$. Among married women other reasons include postpartum amenorrhea/breastfeeding and infrequent or no sex [6].

In 2017 the Zambian government made the Family Planning 2020 Commitment to increase the modern contraceptive prevalence rate among married women to $58 \%$ and ensure that government's contribution to family planning commodities increases by at least 50\% [22]. The services provided from 2013 to 2020 will lead to more than ten million Couple Years of Protection (CYP) [23]. With this in play, there is a need to document, extensively, the factors associated with use of long acting reversible and permanent methods, over time in Zambia. Given the importance of long acting and permanent methods and the need to provide updated information on the trends of use, this study was conceived to assess factors associated with utilization of long acting (Implant and IUCD) and permanent (Vasectomy and Female sterilization) contraceptive methods among married women of reproductive age (15-49 years) in Zambia.

The current international development agenda, under the Sustainable Development Goals (SDG) umbrella stresses the need to ensure equitable access to services for all, including, health, but especially for those in most need. This assertion comes in the wake of concerns about reduced funding for family planning programs in developing countries. As countries experiencing huge population explosions try to expand their reproductive health programs, it is important that attention is given to the factors for and against universal access to services. This analysis was conducted with a desire to understand what has been and is behind the current utilisation of long acting and permanent methods of contraception. This is important as it enables interrogation of the use of these effective methods in a context where many interventions geared at enhancing universal health care, including family planning programs, have been implemented.

\section{Methods}

\section{Data source}

The data for this paper were drawn from the women files from the Zambia Demographic and Health Surveys (ZDHS) for the years 1992, 1996, 2001/2, 2007, and 2013/14. The methodology used in these surveys has been comprehensively described in the respective ZDHS reports by the Zambia Central Statistical Office [13, 24-27]. The main objective of these surveys was to provide information on levels and trends in fertility, childhood mortality, use of family planning methods, and maternal and child health indicators including 
HIV/AIDS. These are nationally representative surveys whose sample design is tailored to provide specific indicators at national and provincial levels. The sampling frames for the 1992 and 1996 surveys were based on 1990 Zambia Census of Population and Housing (ZCPH), while the 2001/2 and 2007 surveys were based on the $2000 \mathrm{ZCPH}$. The 2013/14 survey was based on the $2010 \mathrm{ZCPH}$. Over the years, the sample size for these surveys has increased and so is the size of the eligible women for our analysis. Figure 1 shows that the sample of eligible women (married women aged 15-49) rose by more than 6 times between 1992 and 2013/14.

\section{Variables}

The analytical models used in this paper are adapted from the 2014 paper by Mutombo and Bakibinga, which analysed the effect of joint contraceptive decisions on the use of iLAPMs in Zambia [21]. The dependent variable used is type of contraceptive method. This variable is measured as a dichotomous variable and is coded as short-acting and long-acting. Short acting include all traditional and folkloric methods as well as modern methods that require some action on the part of the user just before sexual intercourse or on daily basis (e.g. condom, spermicides, oral pill). On the other hand, longacting methods comprise of injectable contraceptives, implants and permanent methods. Our paper uses 11 independent variables based on earlier works by Mutombo and Bakibinga [21]. These variables are: "age", "number of living children", "ethnicity", "desire for children", "heard about family planning (FP) in last 12 months", "religion", "type of residence", "respondent's level of education", "partner's level of education", "region",, and "main decision maker on woman's health".

Both "level of education of respondent" and "level of education of partner" are used rather than level of education for the respondent only, as partner education could have some influence on women's decisions [28]. In order to assess some power relations between women and men regarding health issues (contraceptive choices), we used the variable "main decision maker on woman's health". However, information on power relations was not collected for the 1992 and 1997 surveys.

The variable "region" was constructed by grouping the ten provinces into two groups. The grouping was based on proximity to the main line of rail, which to some extent defines access to various services in Zambia. Region 1 comprises of the four provinces (Central, Copperbelt, Lusaka and Southern) where the main development corridor lies. Region 2 covers the other six provinces (Eastern, Luapula, Muchinga, Northern, North Western and Western) outside the main development corridor .

\section{Data analysis}

In order to ascertain the main factors associated with use of iLAPMs the study used different teachniques in analysing the data. Frequencies, cross-tabulations and logistic regressions were used to analyse levels and differentials in use of long-acting family planning methods among women (15-49) in Zambia. The logit of the logistic regression model used can be expressed as follows [29]:

$$
\begin{aligned}
g(\mathrm{x}) & =\ln \left[\frac{\pi(x)}{1-\pi(x)}\right] \\
& =[\pi(x) / 1-\pi(x)] \\
& =\beta_{0}+\beta_{1} x_{1}+\beta_{2} x_{2}+\ldots+\beta_{\mathrm{p}} x_{\mathrm{p}},
\end{aligned}
$$

Where:

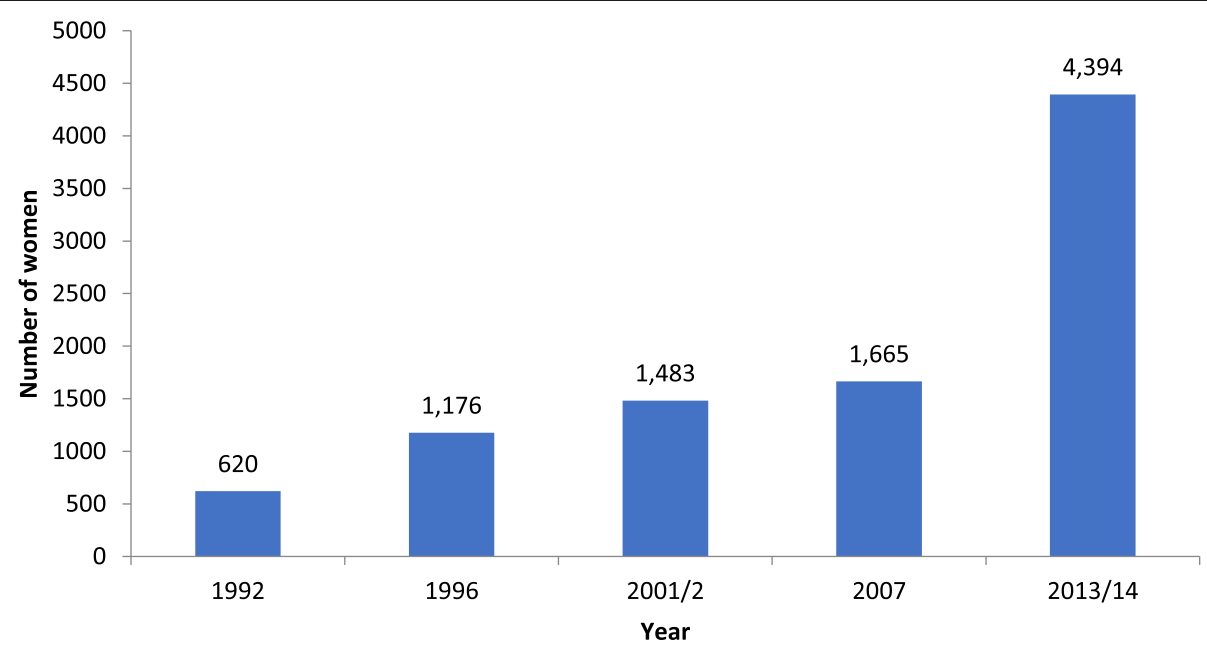

Fig. 1 Number of eligible women for analysis, ZDHS 1992-2014 
$\pi(x)$ the odds for the dependent variable

$x_{1} \ldots x_{\mathrm{p}}$ independent variables

$\beta_{0} \quad$ constant

$\beta_{1} \ldots \beta_{\mathrm{p}}$ regression coefficients

The odds ratio is used to depict the likelihood of using LAPM. A ratio greater than 1 means greater likelihood than the reference category; a ratio less than 1 means lower likelihood than the reference category; and a ratio of 1 means same likelihood as the reference category. In this study, an independent variable is considered significant if its effect on the dependent variable (type of contraceptive method) is statistically significant at the .95 confidence interval (i.e. $p \leq 0.050$ ). Given the multi-stage sampling strategy employed by DHS, all analyses were weighted and missing data handled by pairwise deletion.

\section{Results}

\section{Sample characteristics}

Distribution of married women aged 15-49 by selected background characteristics from 1992 to 2013/4 is shown in Table 1. Majority of women sampled across the five surveys had primary level of education while their partners had secondary and/or higher education. Majority of women interviewed were aged 25-34, had at least five or more children, and desired for more children. In terms of ethnicity, women of Bemba extraction formed the largest proportion of the sampled population. Most of the women interviewed were nonCatholic, were living in rural areas, and had heard about FP in the media during the last 12 months prior to respective surveys. In the earlier survey (2001/2), majority of sampled women had decision on their health made by other people than by the woman herself or in consultation with the partner. However, this changed in the subsequent surveys (2007 and 2013/4) where decision on a woman's health was majorly made by the woman and the partner other than solely by the woman or by other people.

\section{Distribution of iLAPMs users by selected background characteristics from 1992 to 2013/4}

Table 2 is a summary of the distribution of contraceptive users by type of FP method and selected background characteristics. Nationally, apart from the decline in the use of iLAPMs in the early years (18\% in 1992 and 14\% in 1996), Zambia experienced a marked increase in the use of iLAPMs from 1996 to 2013/14 (14\% in 1996, 20\% in $2001 / 2,27 \%$ in 2007 and $57 \%$ in $2013 / 4$ ). Nonetheless, national trends can mask significant differences in the use of iLAPMs by sociodemographic segments. Across all or four out of the five surveys, there were statistically significant differences in the proportion of women who used iLAPMs by their level of education, partner's level of education, maternal age, number of living children, region of residence, type of residence (urban/rural) and exposure to FP messages through media. There were statistically significant differences in the proportion of women who used iLAPMs in two out of the three surveys where data on decision making on a woman's health was available.

To begin with, mothers with secondary and /or higher education were the highest users of iLAPMs in 1992, 1996, 2001/2 and 2007. However, the trend changed in 2013/4 where mothers with primary education were the highest users of iLAPMs compared to mothers in the other educational categories. Trends in the use of iLAPMs by partner's level of education indicate a consistently higher use among those with secondary and/or higher education from 1996 to 2007. In contrast, surveys conducted in 1992 and 2013/4 showed higher use of iLAPMs among partners with no education.

Use of iLAPMs by maternal age showed higher use among women aged 35 years and older in surveys conducted in 1992, 1996, 2001/2 and 2007. The pattern however changed in the 2013/4 survey whereby younger women aged 15-24 posted the highest use of iLAPMs compared to women in the other age groups. Patterns of iLAPMs use disaggregated by number of living children and mother's desire for children showed that women with five or more children and those who were either undecided or wanted no more children were the highest users of iLAPMs in 1992, 1996, 2001/2 and 2007.

Regarding place of residence, women living in Region 1 and urban areas posted higher prevalence in the use of iLAPMs from 1992 to 2007. The pattern was however reversed in 2013/4 whereby women living in Region 2 and rural areas posted significantly higher prevalence in the use of iLAPMs. Results on the use of iLAPMs by exposure to FP messages through media showed in 1996, 2001/2 and 2007, women who had heard about FP in the media during the last 12 months prior to the survey constituted the largest proportion of iLAPMs users compared to those who did not hear about FP in the media. The opposite was nonetheless true in the 2013/4 survey whereby women who had not heard about FP in the media were the highest iLAPMs users compared to those who had heard about FP in the media. In 2001/2 and 2007, women whose decision on their health was made by other people had significantly lower use of iLAPMs as compared to women who either made such a decision on their own or with their partners. The differences in iLAPMs use by decision making on a woman's health was nonetheless not statistically significant in 2013/4. 
Table 1 Percent distribution of married women aged 15-49 by selected background characteristics: 1992-2014

\begin{tabular}{|c|c|c|c|c|c|c|c|c|c|c|}
\hline \multirow[t]{2}{*}{ Background characteristics } & \multicolumn{2}{|l|}{1992} & \multicolumn{2}{|l|}{1996} & \multicolumn{2}{|c|}{$2001 / 2$} & \multicolumn{2}{|l|}{2007} & \multicolumn{2}{|c|}{$2013 / 4$} \\
\hline & $\%$ & $n$ & $\%$ & $n$ & $\%$ & $n$ & $\%$ & $n$ & $\%$ & $n$ \\
\hline \multicolumn{11}{|l|}{ Level of education } \\
\hline None & 11.3 & 70 & 12.8 & 150 & 10.6 & 157 & 10.5 & 175 & 8.2 & 361 \\
\hline Primary & 53.7 & 333 & 58.3 & 686 & 56.9 & 844 & 55.3 & 921 & 52.2 & 2294 \\
\hline Secondary+ & 35.0 & 217 & 28.9 & 340 & 32.5 & 482 & 34.2 & 569 & 39.6 & 1739 \\
\hline \multicolumn{11}{|l|}{ Partner's level of education } \\
\hline None & 5.6 & 35 & 6.3 & 74 & 4.6 & 68 & 5.0 & 84 & 4.8 & 213 \\
\hline Primary & 38.7 & 240 & 41.8 & 491 & 43.0 & 638 & 42.7 & 711 & 36.6 & 1608 \\
\hline Secondary+ & 55.7 & 345 & 51.9 & 611 & 52.4 & 777 & 52.2 & 870 & 58.6 & 2573 \\
\hline \multicolumn{11}{|l|}{ Age } \\
\hline $15-24$ & 26.8 & 166 & 30.7 & 361 & 29.0 & 430 & 25.3 & 421 & 21.4 & 939 \\
\hline $25-34$ & 42.2 & 262 & 40.4 & 475 & 43.2 & 640 & 46.8 & 780 & 45.4 & 1995 \\
\hline $35+$ & 31.0 & 192 & 28.9 & 340 & 27.8 & 413 & 27.9 & 464 & 33.2 & 1460 \\
\hline \multicolumn{11}{|l|}{ Number of living children } \\
\hline$\leq 2$ & 30.8 & 191 & 33.5 & 394 & 34.4 & 511 & 33.4 & 556 & 30.8 & 1353 \\
\hline $3-4$ & 24.8 & 154 & 29.2 & 343 & 31.5 & 467 & 35.6 & 592 & 33.8 & 1483 \\
\hline $5+$ & 44.4 & 275 & 37.3 & 439 & 34.1 & 505 & 31.0 & 517 & 35.4 & 1558 \\
\hline \multicolumn{11}{|l|}{ Desire for children } \\
\hline Wants more & 56.9 & 353 & 60.7 & 714 & 54.9 & 814 & 55.6 & 925 & 56.1 & 2464 \\
\hline Undecided/wants no more & 43.1 & 267 & 39.3 & 462 & 45.1 & 669 & 44.4 & 740 & 43.9 & 1930 \\
\hline \multicolumn{11}{|l|}{ Ethnicity/language group } \\
\hline Bemba & 43.5 & 270 & 36.1 & 424 & 42.7 & 633 & 34.4 & 572 & 42.2 & 1854 \\
\hline Lozi & 6.6 & 41 & 6.2 & 73 & 6.4 & 95 & 8.5 & 141 & 5.8 & 255 \\
\hline North Western (Kaonde, Lunda \& Luvale) & 12.7 & 79 & 17.8 & 210 & 13.2 & 196 & 11.4 & 190 & 10.0 & 439 \\
\hline Nyanja & 21.9 & 136 & 24.4 & 287 & 23.0 & 341 & 30.2 & 503 & 26.1 & 1148 \\
\hline Tonga & 15.3 & 94 & 15.5 & 182 & 14.7 & 218 & 15.5 & 259 & 15.9 & 698 \\
\hline \multicolumn{11}{|l|}{ Religion/Denomination } \\
\hline Catholic & 29.5 & 183 & 24.0 & 282 & 23.9 & 355 & 19.2 & 319 & 17.7 & 778 \\
\hline Non-Catholic & 70.5 & 437 & 76.0 & 894 & 76.1 & 1128 & 80.8 & 1346 & 82.3 & 3616 \\
\hline \multicolumn{11}{|l|}{ Region } \\
\hline Region 1 (Central, Copperbelt, Lusaka \& Southern) & 63.7 & 395 & 48.6 & 571 & 48.5 & 719 & 48.2 & 802 & 43.6 & 1914 \\
\hline Region 2 (Eastern, Luapula, Muchinga, Northern, North Western \& Western) & 36.3 & 225 & 51.4 & 605 & 51.5 & 764 & 51.8 & 863 & 56.4 & 2480 \\
\hline \multicolumn{11}{|l|}{ Type of residence } \\
\hline Urban & 58.9 & 365 & 44.0 & 517 & 40.4 & 600 & 44.4 & 740 & 47.7 & 2098 \\
\hline Rural & 41.1 & 255 & 56.0 & 659 & 59.6 & 883 & 55.6 & 925 & 52.3 & 2296 \\
\hline \multicolumn{11}{|l|}{ Heard about FP in the media during last 12 months } \\
\hline Yes & 29.8 & 185 & 63.2 & 743 & 57.6 & 855 & 50.8 & 846 & 43.3 & 1903 \\
\hline No & 70.2 & 435 & 36.8 & 433 & 42.4 & 628 & 49.2 & 819 & 56.7 & 2491 \\
\hline \multicolumn{11}{|l|}{ Main decision maker on woman's health } \\
\hline Woman alone & - & - & - & - & 31.1 & 461 & 31.1 & 517 & 31.6 & 1386 \\
\hline Woman with partner & - & - & - & - & 11.7 & 173 & 36.7 & 611 & 43.7 & 1921 \\
\hline Other & - & - & - & - & 57.2 & 849 & 32.2 & 537 & 24.7 & 1087 \\
\hline Total & 100.0 & 620 & 100.0 & 1176 & 100.0 & 1483 & 100.0 & 1665 & 100.0 & 4394 \\
\hline
\end{tabular}


Table 2 Percent distribution of contraceptive users by type of FP method and selected background characteristics: 1992-2014

\begin{tabular}{|c|c|c|c|c|c|c|c|c|c|c|}
\hline \multirow[t]{3}{*}{ Background characteristics } & \multicolumn{10}{|c|}{ Type of FP method } \\
\hline & \multicolumn{2}{|l|}{1992} & \multicolumn{2}{|l|}{1996} & \multicolumn{2}{|l|}{$2001 / 2$} & \multicolumn{2}{|l|}{2007} & \multicolumn{2}{|l|}{ 2013/4 } \\
\hline & iLAPMs & Other & iLAPMs & Other & iLAPMs & Other & iLAPMs & Other & iLAPMs & Other \\
\hline Level of education & $* *$ & $* *$ & $* * *$ & $* * *$ & $* * *$ & $* * *$ & $* *$ & $* *$ & * & $*$ \\
\hline None & 17.4 & 82.6 & 8.0 & 92.0 & 13.0 & 87.0 & 20.4 & 79.6 & 52.2 & 47.8 \\
\hline Primary & 13.6 & 86.4 & 11.1 & 88.9 & 17.9 & 82.1 & 25.0 & 75.0 & 58.8 & 41.2 \\
\hline Secondary+ & 23.9 & 76.1 & 20.3 & 79.7 & 25.5 & 74.5 & 31.1 & 68.9 & 55.8 & 44.2 \\
\hline Partner's level of education & * & * & $* *$ & $* *$ & $* * *$ & $* * *$ & $* * *$ & $* * *$ & * & * \\
\hline None & 31.2 & 68.8 & 9.5 & 90.5 & 4.7 & 95.3 & 20.0 & 80.0 & 64.8 & 35.2 \\
\hline Primary & 12.8 & 87.2 & 10.2 & 89.8 & 16.1 & 83.9 & 22.0 & 78.0 & 56.1 & 43.9 \\
\hline Secondary+ & 19.9 & 80.1 & 16.1 & 46.8 & 24.1 & 75.9 & 30.8 & 69.2 & 56.5 & 43.5 \\
\hline Age & $* * *$ & $* * *$ & $* * *$ & $* * *$ & $* * *$ & $* * *$ & $* *$ & $* *$ & $* * *$ & $* * *$ \\
\hline $15-24$ & 1.7 & 98.3 & 3.1 & 96.9 & 9.7 & 90.3 & 25.1 & 74.9 & 65.2 & 34.8 \\
\hline $25-34$ & 10.0 & 90.0 & 8.0 & 92.0 & 18.5 & 81.5 & 23.3 & 76.7 & 56.8 & 43.2 \\
\hline $35+$ & 40.9 & 59.1 & 32.4 & 67.6 & 33.5 & 66.5 & 32.6 & 67.4 & 52.2 & 47.8 \\
\hline Number of living children & $* * *$ & $* * *$ & $* * *$ & $* * *$ & $* * *$ & $* * *$ & $* *$ & $* *$ & & \\
\hline$\leq 2$ & 10.8 & 89.2 & 5.6 & 94.4 & 12.9 & 87.1 & 25.0 & 75.0 & 57.7 & 42.3 \\
\hline $3-4$ & 11.6 & 88.4 & 12.0 & 88.0 & 16.7 & 83.3 & 23.0 & 77.0 & 55.1 & 44.9 \\
\hline $5+$ & 26.6 & 73.4 & 22.7 & 77.3 & 30.9 & 69.1 & 32.0 & 68.0 & 58.3 & 41.7 \\
\hline Desire for children & $* * *$ & $* * *$ & $* * *$ & $* * *$ & $* * *$ & $* * *$ & $* * *$ & $* * *$ & & \\
\hline Wants more & 3.5 & 96.5 & 3.9 & 96.1 & 10.6 & 89.4 & 22.9 & 77.1 & 56.4 & 43.6 \\
\hline Undecided/wants no more & 35.5 & 64.5 & 27.9 & 72.1 & 31.7 & 68.3 & 30.8 & 69.2 & 58.1 & 41.9 \\
\hline Ethnicity/language group & & & & & & & & & $* *$ & $* *$ \\
\hline Bemba & 17.7 & 82.3 & 14.7 & 85.3 & 19.8 & 80.2 & 26.8 & 73.2 & 56.9 & 43.1 \\
\hline Lozi & 17.1 & 82.9 & 9.4 & 90.6 & 17.0 & 83.0 & 20.4 & 79.6 & 55.3 & 44.7 \\
\hline North Western (Kaonde, Lunda \& Luvale) & 19.7 & 80.3 & 12.3 & 87.7 & 20.0 & 80.0 & 34.8 & 65.2 & 65.1 & 34.9 \\
\hline Nyanja & 12.7 & 87.3 & 12.0 & 88.0 & 20.6 & 79.4 & 23.9 & 76.1 & 58.5 & 41.5 \\
\hline Tonga & 16.8 & 83.2 & 14.7 & 85.3 & 23.0 & 77.0 & 28.2 & 71.8 & 53.5 & 46.6 \\
\hline Religion/Denomination & & & & & & & * & * & & \\
\hline Catholic & 18.9 & 81.1 & 11.0 & 89.0 & 17.4 & 82.6 & 21.7 & 78.3 & 58.3 & 41.7 \\
\hline Non-Catholic & 17.5 & 82.5 & 14.6 & 85.4 & 20.9 & 60.1 & 27.6 & 72.4 & 56.8 & 43.2 \\
\hline Region & $* *$ & $* *$ & $* * *$ & $* * *$ & $* * *$ & $* * *$ & $* *$ & $* *$ & $* *$ & $* *$ \\
\hline Region 1 (Central, Copperbelt, Lusaka \& Southern) & 20.5 & 79.5 & 18.7 & 81.3 & 24.0 & 76.0 & 29.1 & 70.9 & 55.3 & 44.7 \\
\hline Region 2 (Eastern, Luapula, Muchinga, Northern, North Western \& Western) & 11.7 & 88.3 & 6.8 & 93.2 & 14.6 & 85.4 & 23.3 & 76.7 & 59.7 & 40.3 \\
\hline Type of residence & $* * *$ & $* * *$ & $* * *$ & $* * *$ & $* * *$ & $* * *$ & $* *$ & $* *$ & $* *$ & $* *$ \\
\hline Urban & 22.1 & 77.9 & 19.5 & 80.5 & 26.7 & 73.3 & 30.7 & 69.3 & 54.8 & 45.2 \\
\hline Rural & 10.0 & 90.0 & 7.5 & 92.5 & 14.2 & 85.8 & 23.4 & 76.6 & 59.0 & 41.0 \\
\hline Heard about FP in the media during last 12 months & & & $* *$ & $* *$ & $* * *$ & $* * *$ & $* *$ & $* *$ & $* * *$ & $* * *$ \\
\hline Yes & 20.0 & 80.0 & 16.0 & 84.0 & 24.2 & 75.8 & 29.5 & 70.5 & 53.4 & 46.6 \\
\hline No & 16.8 & 83.2 & 9.2 & 90.8 & 13.5 & 86.5 & 23.4 & 76.6 & 59.6 & 40.4 \\
\hline Main decision maker on woman's health & & & & & ** & $* *$ & ** & ** & & \\
\hline Woman alone & - & - & - & - & 24.3 & 75.7 & 27.5 & 72.5 & 56.0 & 44.0 \\
\hline Woman with partner & - & - & - & - & 22.5 & 77.5 & 30.4 & 69.6 & 57.1 & 42.9 \\
\hline Other & - & - & - & - & 17.3 & 82.7 & 21.2 & 78.8 & 58.3 & 41.7 \\
\hline Total & 17.9 & 82.1 & 13.7 & 86.3 & 20.3 & 79.7 & 26.5 & 73.5 & 57.2 & 42.8 \\
\hline
\end{tabular}

${ }^{*}, p<.050 ;{ }^{* *}, p<.010 ; * * *, p<.001$ 


\section{Likelihood of married women using iLAPMs from 1992 to} 2013/4

Table 3 shows unadjusted and adjusted logistic regression models assessing the likelihood of women using iLAPMs in 1992, 1996, 2001/2, 2007 and 2013/ 4. Beginning with unadjusted models, in four out of the five surveys, there were statistically significant associations between the use of iLAPMs and maternal and partner's level of education, maternal age, number of living children, desire for children, region of residence, type of residence (urban/rural), and exposure to FP messages through media. There was a statistically significant association between the use of iLAPMs and decision making on a woman's health in 2007 only as this variable was insignificant on the use of iLAPMs in 2001/22013/4. In 2007, women who made decisions on their health alone $((\mathrm{AOR}=$ 1.394, 95\% CI 1.044-1.852) and those who made such decisions in consultation with their partners ( $\mathrm{AOR}=1.506,95 \%$ CI $1.139-1.992)$ were more likely to use iLAPMs compared to women whose decision on their health was made by other people.

In the adjusted models, maternal education was significantly associated with iLAPMs use only in the 1996 and 2013/4 surveys. In 1996, women with primary $(\mathrm{AOR}=0.544,95 \% \mathrm{CI} 0.342-0.866)$ or no education $(\mathrm{AOR}=0.411,95 \% \mathrm{CI} 0.173-0.973)$ were less likely to use iLAPMs compared to women with secondary and/or higher education. Similarly, in 2013/4, women with no education were less likely to use iLAPMs (AOR $=0.709$, 95\% CI 0.548-0.918) compared to women with secondary and/or higher education. Partner's level of education was significantly associated with the likelihood of iLAPMs use only in the 2001/2 and 2007 surveys. Women whose partners had no education in 2001/2 (AOR $=0.226,95 \%$ CI $0.066-0.772$ ) or had primary level education in 2007 (AOR $=0.731,95 \%$ CI $0.560-0.954$ ) were significantly less likely to use iLAPMs compared to women with partners with secondary and/or higher education.

Controlling for other covariates in the regression model, age was significantly associated with iLAPMs use in four out of the five surveys. In 1992 (AOR $=0.047$, 95\% CI 0.011-0.198; AOR $=0.189,95 \%$ CI 0.098-0.364), 1996 (AOR 0.132, 95\% CI 0.055-0.313; AOR 0.213, 95\% CI $0.128-0.356)$ and $2001 / 2 \quad(\mathrm{AOR}=0.455, \quad 95 \% \mathrm{CI}$ $0.258-0.804$; $\mathrm{AOR}=0.618,95 \%$ CI $0.431-0.885$ ), younger women aged 15-24 and 25-34 were less likely to use iLAPMs compared to women aged 35 years and older. The pattern was however different in 2013/4 where younger women aged $15-24(\mathrm{AOR}=3.212$, 95\% CI $2.515-4.103)$ and $25-34 \quad(\mathrm{AOR}=1.771,95 \% \mathrm{CI}$ 1.493-2.101) were three and two times, respectively, likely to use iLAPMs compared to women aged 35 years and older.
Number of living children in a household was significantly associated with the likelihood of women using iLAPMs in 2001/2 and 2013/4. In 2001/2 and 20,013/4, women with $3-4$ children $((\mathrm{AOR}=0.671,95 \% \mathrm{CI} 0.462-$ $0.976)$ and $(\mathrm{AOR}=0.713,95 \% \mathrm{CI} 0.600-0.846)$, respectively) were less likely to use iLAPMs compared to those with five or more children. Equally, women with two or less children $((\mathrm{AOR}=0.594,95 \% \mathrm{CI} 0.474-0.744))$ were significantly less likely to use iLAPMs in 2013/4 compared to those with five or more children. Mother's desire for children was significantly associated with iLAPMs use in all the surveys. Women who wanted more children were significantly less likely to use iLAPMs in $1992(\mathrm{AOR}=0.18295 \% \mathrm{CI} 0.087-0.380), 1996(\mathrm{AOR}=$ 0.238 95\% CI0.138-0.408), 2001/2 (AOR $=0.440,95 \% \mathrm{CI}$ $0.312-0.621), 2007$ (AOR $=0.755,95 \%$ CI 0.571-0.999), and $2013 / 4$ (AOR $=0.695$, 95\% CI 0.595-0.812).

Considering other possible covariates of iLAPMs use, a woman's place of residence was significantly associated with iLAPMs use only in the $2001 / 2$ survey. Women in urban areas $(\mathrm{AOR}=1.537,95 \% \mathrm{CI} 1.088-2.172)$ were two times morelikely to use iLAPMs compared to women residing in rural areas. The Zambian data also show some interesting trends on the significance of exposure to FP messages on the use of iLAPMs. Regarding access to FP messages, the data show that while a woman's exposure to FP messages in last 12 months was not significant on the use of iLAPMS in the prior surveys, the data for the 2013/4 survey was significantly associated with the likelihood of using iLAPMs. Women who had heard about FP in during the 12 months to their interview $(\mathrm{AOR}=0.814,95 \%$ CI $0.717-0.924)$ were less likely to use iLAPMs compared to those who had not heard about FP during the reference period. A similar trend is also notable by ethnicity. Whereas earlier surveys show no significance on the use of iLAPMS by ethnicity, the 2013/14 survey reveals significant differences among ethnic groups. While the Bemba and Lozi women exhibit higher likelihood of using iLAPMs than their Tonga counterparts (reference group), the relationship is statistically insignificant. On the other hand, women of North Western ethnicities (Kaonde, Lunda and Luvale) (AOR $=1.753$, 95\% CI 1.310-2.345) and those of Nyanja-Speaking groups (AOR $=1.273,95 \%$ CI 1.039-1.559) are significantly more likely to use iLAPMs than their Tonga counterparts, with North Westerners almost twice more likely to use iLAPMs than Tonga women.

\section{Discussion}

This paper explored the factors associated with use of injectables, long acting and permanent methods of contraception among married women in Zambia. Over the years, the use of iLAPMs has significantly increased, 
Table 3 Likelihood of using iLAPMs among married female contraceptive users by selected background characteristics: 1992-2014

\begin{tabular}{|c|c|c|c|c|c|c|c|c|c|c|}
\hline \multirow[t]{3}{*}{ Background characteristics } & \multicolumn{10}{|c|}{ Unadjusted and Adjusted Odds ratios } \\
\hline & \multicolumn{2}{|l|}{1992} & \multicolumn{2}{|l|}{1996} & \multicolumn{2}{|l|}{$2001 / 2$} & \multicolumn{2}{|l|}{2007} & \multicolumn{2}{|l|}{ 2013/4 } \\
\hline & $\overline{O R}$ & AOR & $\overline{O R}$ & AOR & OR & AOR & OR & $\mathrm{AOR}$ & OR & AOR \\
\hline \multicolumn{11}{|l|}{ Respondent's level of education } \\
\hline None & 0.663 & 0.709 & $0.325^{* *}$ & $0.411^{*}$ & $0.438^{* *}$ & 0.695 & $0.564^{* *}$ & 0.709 & 0.867 & $0.709^{* *}$ \\
\hline Primary & $0.502^{* *}$ & 1.010 & $0.488^{* * *}$ & $0.544^{*}$ & $0.638^{* *}$ & 0.869 & $0.737^{* *}$ & 0.885 & $1.130^{*}$ & 0.985 \\
\hline Secondary $+^{+}$ & - & - & - & - & - & - & - & - & - & - \\
\hline \multicolumn{11}{|l|}{ Partner's level of education } \\
\hline None & 1.736 & 3.070 & 0.546 & 0.959 & $0.154^{* *}$ & $0.226^{*}$ & $0.556^{*}$ & 0.689 & $1.418^{*}$ & 1.272 \\
\hline Primary & $0.599^{*}$ & 0.751 & $0.590^{* *}$ & 0.839 & $0.604^{* * *}$ & 0.844 & $0.632^{* * *}$ & $0.731^{*}$ & 0.983 & 0.915 \\
\hline Secondary+ & - & - & - & - & - & - & - & - & - & - \\
\hline \multicolumn{11}{|l|}{ Age } \\
\hline $15-24$ & $0.028^{* * *}$ & $0.047^{* * *}$ & $0.069^{* * *}$ & $0.132^{* * *}$ & $0.214^{* * *}$ & $0.455^{* *}$ & $0.967^{*}$ & 1.046 & $1.716^{* * *}$ & $3.212^{* * *}$ \\
\hline $25-34$ & $0.161^{* * *}$ & $0.189^{* * *}$ & $0.183^{* * *}$ & $0.213^{* * *}$ & $0.449^{* * *}$ & $0.618^{* *}$ & $0.631^{* * *}$ & 0.852 & $1.206^{* *}$ & $1.771^{* * *}$ \\
\hline $35+^{+}$ & - & - & - & - & - & - & - & - & - & - \\
\hline \multicolumn{11}{|l|}{ Number of living children } \\
\hline$\leq 2$ & $0.330^{* * *}$ & 2.401 & $0.199^{* * *}$ & 1.307 & $0.333^{* * *}$ & 0.763 & $0.710^{* *}$ & 0.745 & 0.976 & $0.594^{* * *}$ \\
\hline $3-4$ & $0.360^{* * *}$ & 1.024 & $0.460^{* * *}$ & 1.517 & $0.451^{* * *}$ & $0.671^{*}$ & $0.637^{* *}$ & 0.730 & 0.877 & $0.713^{* * *}$ \\
\hline $5+^{+}$ & - & - & - & - & - & - & - & - & - & - \\
\hline \multicolumn{11}{|l|}{ Desire for children } \\
\hline Wants more & $0.066^{* * *}$ & $0.182^{* * *}$ & $0.105^{* * *}$ & $0.238^{* * *}$ & $0.255^{* * *}$ & $0.440^{* * *}$ & $0.667^{* * *}$ & $0.755^{*}$ & 0.936 & $0.695^{* * *}$ \\
\hline Undecided/wants no more ${ }^{\dagger}$ & - & - & - & - & - & - & - & - & - & - \\
\hline \multicolumn{11}{|l|}{ Ethnicity/language group } \\
\hline Bemba & 1.068 & 1.173 & 1.004 & 0.868 & 0.823 & 0.955 & 0.931 & 0.878 & 1.150 & 1.160 \\
\hline Lozi & 1.059 & 1.749 & 0.618 & 0.561 & 0.693 & 0.891 & 0.640 & 0.595 & 1.074 & 1.104 \\
\hline North Western (Kaonde, Lunda \& Luvale) & 1.251 & 2.152 & 0.834 & 1.452 & 0.848 & 1.097 & 1.361 & 1.312 & $1.627^{* * *}$ & $1.753^{* * *}$ \\
\hline Nyanja & 0.703 & 0.560 & 0.811 & 1.105 & 0.864 & 0.978 & 0.793 & 0.898 & $1.230^{*}$ & $1.273^{*}$ \\
\hline Tonga $^{\dagger}$ & - & - & - & - & - & - & - & - & - & - \\
\hline \multicolumn{11}{|l|}{ Religion/Denomination } \\
\hline Catholic & 1.084 & 1.150 & 0.733 & 0.702 & 0.799 & 0.779 & 0.728 & 0.813 & 1.067 & 1.027 \\
\hline Non-Catholic ${ }^{\dagger}$ & - & - & - & - & - & - & - & - & - & - \\
\hline \multicolumn{11}{|l|}{ Region } \\
\hline Region 1 (Central, Copperbelt, Lusaka \& Southern) & $1.967^{* *}$ & 1.099 & $3.124^{* * *}$ & 1.685 & $1.838^{* * *}$ & 1.230 & $1.353^{* *}$ & 0.963 & $0.833^{* *}$ & 0.979 \\
\hline $\begin{array}{l}\text { Region } 2 \text { (Eastrn, Luapula, Muchinga, Northern, North Western }^{\text {\& Western) }}{ }^{\dagger}\end{array}$ & - & - & - & - & - & - & - & - & - & - \\
\hline \multicolumn{11}{|l|}{ Type of residence } \\
\hline Urban & $2.548^{* * *}$ & 2.096 & $2.956^{* * *}$ & 1.625 & $2.212^{* * *}$ & $1.537^{*}$ & $1.453^{* *}$ & 1.119 & $0.841^{* *}$ & 0.892 \\
\hline Rural $^{\dagger}$ & - & - & - & - & - & - & - & - & - & - \\
\hline \multicolumn{11}{|l|}{ Heard about FP in the media during last 12 months } \\
\hline Yes & 1.241 & 1.151 & $1.879^{* *}$ & 1.016 & $2.060^{* * *}$ & 1.258 & $1.366^{* *}$ & 1.124 & $0.776^{* * *}$ & $0.814^{* *}$ \\
\hline $\mathrm{No}^{+}$ & - & - & - & - & - & - & - & - & - & - \\
\hline \multicolumn{11}{|l|}{ Main decision maker on woman's health } \\
\hline Woman alone & - & - & - & - & $1.523^{* *}$ & 1.270 & $1.411^{*}$ & $1.390^{*}$ & 0.905 & 0.963 \\
\hline Woman with partner & - & - & - & - & 1.371 & 1.416 & $1.628^{* * *}$ & $1.506^{* *}$ & 0.948 & 1.010 \\
\hline Other $^{\dagger}$ & - & - & - & - & - & - & - & - & - & - \\
\hline Constant & - & 0.420 & - & 0.501 & - & $0.469^{*}$ & - & $0.558^{*}$ & - & $1.355^{*}$ \\
\hline
\end{tabular}

${ }^{*}, p<.050 ;{ }^{* *}, p<.010 ;{ }^{* * *}, p<.001 ;$ OR Unadjusted Odds Ratios, AOR Adjusted Odds Ratios; + , and Higher; $\dagger$, Reference Group 
which can have a positive influence on the socioeconomic development of countries [30]. However, there is need for more research to understand the dynamics of contraceptive use among Zambian women as trends appear inconsistent. These trends, point to issues of access among the vulnerable groups. By 1996 (five years after country reverted to multi-party democracy), Zambia had stabilised economically with a better functioning health system than the situation in 1992 (a year after the change of government). By 2001/2, the country was struggling with a huge external debt that affected health service delivery (including family planning) in a number of ways. In 2007, the country had just gotten debt relief from the HIPC initiative and the effects of this relief had not fully trickled to most parts of the country. The 2013/14 results show much higher access to iLAPMs than previously, possibly owing to transfer of certain services from the Ministry of Health to the Ministry of Community Development in 2011. With a well performing economy between 2006 and 2011, the government was able to roll out a range of health services (including family planning) to the most vulnerable groups through static and mobile health services.

Data show that use of modern contraceptives in Zambia has been significantly associated with employment status, education level and residence, as elsewhere. For instance, results from different regions in Ethiopia found that women's level of education, number of live children, occupation, and discussions with health care providers were significantly positively associated with the use of LAPMs [31-33]. In this study, maternal education was found to be significantly associated with iLAPMs use only in the 1996 and 2013/4 surveys. In both surveys, women with primary or no education were less likely to use iLAPMs compared to women with secondary and/or higher education. Similarly, it has also been reported that utilisation of iLAPMs were significantly associated with women who had secondary school, college and above education [34]. Partner's level of education significantly predicted the likelihood of iLAPMs use only in the 2001/2 and 2007 surveys. Women with partners with no education in 2001/2 or had primary level of education in 2007 were significantly less likely to use iLAPMs compared to women with partners with secondary and/or higher education.

Maternal age was a significantly associated with iLAPMs use in four out of the five surveys after controlling for other factors in the regression model. In the earlier surveys 1992, 1996 and 2001/2, younger women aged 15-24 and 25-34 were less likely to use iLAPMs compared to women aged 35 years and older. However, in 2013/4 where younger women aged 15-24 and 25-34 were three and two times, respectively, more likely to use iLAPMs compared to women aged 35 years and older. This could be explained by younger women wanting to have less children. The 2014 Zambia Demographic and Health Survey reported that the ideal number of children for women 15-34 was less than those above 35 [13]. This is an important finding as it speaks to the younger generation and the possibility that efforts to reach young people to use ILAPMs is bearing fruits in Zambia.

Additionally, the desire to limit child bearing increases with the number of living children [13]. The number of living children in a household was significantly associated with the likelihood of women using iLAPMs in 2001/2, 2007 and 2013/4. In 2001/2, 2007 and 20,013/4, women with 3-4 children) were less likely to use iLAPMs compared to those with five or more children. Equally, women with two or less children were less likely to use iLAPMs in 2013/4 compared to those with five or more children. Additionally, women who wanted more children were significantly less likely to use iLAPMs as compared to those who were undecided or wanted no more across all the surveys. According to Van Lith et al. women who have met or exceeded their ideal parity are more likely to use permanent methods [8].

Considering other possible predictors of iLAPMs use, a woman's place of residence was a significant covariate of iLAPMs use only in the 2001/2 survey. Women in urban areas were two times more likely to use iLAPMs compared to women residing in rural areas. This is consistent with what has been reported in the literature as women living in urban areas are likely to have better access to family planning services [35]. Important to note is the lack of statistically significant differences between urban and rural areas in the later surveys. It looks like in the early years (2002 and before) iLAPMs use in rural areas was significantly lower as compared to urban. The lack of any significant differences in the later surveys could mean there has been an increase in iLAPMs use in rural areas and the gap between urban and rural areas has significantly narrowed in the recent past.

Woman's exposure to FP messages 12 months prior to the 2013/4 survey was significantly associated with the likelihood of iLAPMs use. Women who had heard about FP were less likely to use iLAPMs compared to those who had not heard about FP in the last 12 months. This is a new trend in Zambia and is inconsistent with Melka et al. (2015) who found that having access to media platforms like radio/TV were positively associated with the use of iLAPMs [33]. A possible explanation would be the age at which women get exposed to messages about family planning. Weidert et al. [36] reported that women 15-24 years were more likely to use contraception if they had a FP message, but there was no association with contraceptive use in older women. It can also be argued that given the nature of iLAPMs, particularly the 
long-acting and permanent methods, a woman who heard the message about FP more than 12 months before the survey may still be on any of these methods even when they did not hear about FP during the reference period at the time of the survey.

Another new trend is the significance of ethnicity on use of iLAPMs. It is not immediately clear why women of North Western ethnicities (Kaonde, Lunda and Luvale) and those of Nyanja-Speaking groups are significantly more likely to use iLAPMs than their Tonga counterparts. It would appear that there are some underlying cultural myths/beliefs about FP in general and effects of iLAPMS in particular within socio-ethnic networks. Understanding this complex issue would require a separate investigation.

\section{Conclusion}

This study has established that women's desire for children is the main factor influencing use of iLAPMs in Zambia. Women who still want to have children are less likely to use iLAPMs even though the odds of using these methods among these women increased between 1992 and 2014. This indicates that most of this increase is due to the desire by these women to space births rather than stop having children. The 2013/2014 data also suggest an increase in access to iLAPMs among the less privileged women i.e. those in rural areas and those with low levels of education. This trend appears to have stemmed from the scaling up of family planning programmes to cover rural communities. Demystifying family planning through culturally appropriate messaging and targeting women in the immediate postpartum period could be powerful tools in increasing acceptability of iLAPMSs in the country. If Zambia is to achieve the FP2020 target, greater effort should be invested into family planning programs that will empower women to be able to make informed decisions about the contraceptive methods that they use. As Zambia and other countries in SSA develop their strategies to achieve universal health access, under the SDG agenda, it is important to take stock of what influences use of these very effective methods over time and which factors can be enhanced to ensure that no woman is left behind.

\section{Acknowledgements}

We are grateful to Macro International Inc. for availing us the data sets.

\section{Authors' contributions}

This work was a collaborative effort between the authors. PB conceptualised the study, participated in the interpretation of the data, managed the literature searches and wrote part of the first draft of the manuscript. NM \& DM partly conceptualised the study, ran the statistical analysis and wrote part of the first draft of the manuscript. LK contributed the literature searches and writing of the manuscript. All the authors read, reviewed, and approved of the final manuscript.

\section{Funding}

The authors received no funding for this work.

\section{Availability of data and materials}

Data used in this study is publicly available and can be accessed through application to MEASURE DHS. Syntaxes and outputs generated can be made available upon request to the corresponding author.

Ethics approval and consent to participate

Not applicable

Consent for publication

Not applicable

\section{Competing interests}

The authors declare that they have no competing interests.

\section{Author details}

'African Population \& Health Research Center, P.O.Box 10787, Nairobi 00100, Kenya. ${ }^{2}$ Population Council, Nairobi, Kenya. ${ }^{3}$ University of Zambia, Lusaka, Zambia.

Received: 24 January 2019 Accepted: 21 May 2019

Published online: 06 June 2019

\section{References}

1. PRB, 2018 World Population Data Sheet. 2018, Population Reference Bureau (PRB): https://www.prb.org/2018-world-population-data-sheet-with-focus-onchanging-age-structures/.

2. Bongaarts J, Casterline J. Fertility transition: is sub-Saharan Africa different? Popul Dev Rev. 2013;38(Suppl 1):153-68.

3. Shapiro D, Hinde A. On the pace of fertility decline in sub-Saharan Africa. Demogr Res. 2017;37(40):1327-38.

4. Bank, W., Fertility rate, total (births per woman). 2018, The World Bank: https://data.worldbank.org/indicator/SP.DYN.TFRT.IN?locations=ZG.

5. Institute, G., Adding it up: Investing in Contraception and Maternal and Newborn Health, 2017. Fact Sheet. 2017, Guttmacher Institute: https://www. guttmacher.org/sites/default/files/factsheet/adding-it-up-contraceptionmnh-2017.pdf.

6. Sedgh G, Singh S, Hussain R. Intended and unintended pregnancies worldwide in 2012 and recent trends. Stud Fam Plan. 2014;45(3):301-14.

7. Westoff, C.F., Unmet Need for Modern Contraceptive Methods, in DHS Analytical Studies No. 28. 2012, The DHS Program: https://www.dhsprogram. com/pubs/pdf/AS28/AS28.pdf.

8. Van Lith LM, Yahner M, Bakamjian L. Women's growing desire to limit births in sub-Saharan Africa: meeting the challenge. Glob Health Sci Pract. 2013;1(1):97-107.

9. Emina JB, Chirwa T, Kandala NB. Trend in the use of modern contraception in sub-Saharan Africa: does women's education matter? Contraception. 2014:90(2):154-61.

10. Bradley SEK, Croft TN, Rutstein SO. The impact of contraceptive failure on unintended births and induced abortions: Estimates and strategies for reduction, in DHS Analytical Studies No. 22. Calverton, Maryland, USA: ICF Macro; 2011.

11. Lauro, D., Abortion and contraceptive use in sub-Saharan Africa: how women plan their families. Afr J Reprod Health, 2011. 15(1).

12. Creanga AA, et al. Low use of contraception among poor women in Africa: an equity issue. Bull World Health Organ. 2011;89(4):258-66.

13. Central Statistical Office (CSO) [Zambia], M.o.H.M.Z., and ICF International. Zambia Demographic and Health Survey 2013-14. Rockville, Maryland, USA Central Statistical Office, Ministry of Health, and ICF International; 2014.

14. Wulifan JK, et al. A scoping review on determinants of unmet need for family planning among women of reproductive age in low and middle income countries. BMC Women's Health. 2016;16:2.

15. Pasha $\mathrm{O}$, et al. Postpartum contraceptive use and unmet need for family planning in five low-income countries. Reprod Health. 2015:12(Suppl 2):S11.

16. Ashraf $\mathrm{N}$, Field $\mathrm{E}$, Lee J. Household bargaining and excess fertility: an experimental study in Zambia. Am Econ Rev. 2014;104(7):2210-37.

17. Phiri M, Banda C. Trends in modern contraceptive use and factors associated with current use in Zambia: Evidence from DHS data 1992-2014. 2015: http://uaps2015.princeton.edu/papers/150529.

18. FHI, Addressing unmet need for family planning in Africa: Long- acting and permanent methods. 2008, Family Health International-FHI: Research Triangle Park, NC. 
19. WHO, Strategies to increase use of long-acting and permanent contraception, in From Evidence to Policy. Expanding access to family planning. Geneva: WHO Department of Reproductive Health and Research; 2012.

20. Alemayehu ST, Abebach AW. Determinants of long acting contraceptive use among reproductive age women in Ethiopia: evidence from EDHS 2011. Sci J Pub Health. 2014;(3).

21. Mutombo N, Bakibinga P. The effect of joint contraceptive decisions on the use of Injectables, long-acting and permanent methods (ILAPMs) among married female (15-49) contraceptive users in Zambia: a cross-sectional study. Reprod Health. 2014;11(1):51.

22. Zambia, G.o., Family planning 2020 commitment. 2017: http://ec2-54-210230-186.compute-1.amazonaws.com/wp-content/uploads/2018/02/Zambia_ FP2020_Commitment_2017.pdf.

23. Zambia, G.o., Family Planning Services: Integrated Family Planning Scale-up Plan 2013-2020. 2013, Ministry of Community Development Mother and Child Health: Lusaka, Zambia.

24. Inc, C.S.O.Z.a.M.o.H.a.M.I. Zambia Demographic and Health Survey 1996. Calverton, Maryland: Central Statistical Office and Macro International Inc; 1997.

25. Central Statistical Office [Zambia], M.II. Zambia Demographic and Health Survey 2007: Key Findings. Calverton, Maryland, USA: CSO and Macro International Inc; 2009.

26. Inc, C.Z.a.M. Zambia Demographic and Health Survey 1992: Summary Report. Calverton, Maryland, USA: Central Statistical Office (CSO Zambia) and Macro International Inc; 1992

27. Central Statistical Office [Zambia], C.B.o.H.Z., and ORC Macro. Zambia Demographic and Health Survey 2001-2002. Calverton, Maryland, USA: central statistical office, central Board of Health, and ORC macro; 2003.

28. Gubhaju B. The influence of Wives' and Husbands' education levels on contraceptive method choice in Nepal, 1996-2006. Int Perspect Sex Reprod Health. 2009;35(4):176-85.

29. Hosmer WD, Lemeshow S. Applied logistic regression. Toronto: John Wiley \& Sons Inc; 2000.

30. Takele A, Degu G, Yitayal M. Demand for long acting and permanent methods of contraceptives and factors for non-use among married women of Goba town, bale zone, south East Ethiopia. Reprod Health. 2012;9(26).

31. Alemu ST. Factors Affecting Intention to Use Long Acting and Permanent Contraceptive Methods among Married Women of Reproductive Age Groups in Western Ethiopia: A Community Based Cross Sectional Study. Fam Med Med Sci Res. 2015;4(1).

32. Abajobir AA. Intention to use long-acting and permanent family planning methods among married 15-49 years women in Debremarkos town, Northwest Ethiopia. Fam Med Med Sci Res. 2014;(3):145.

33. Melka AS, Beyene TT, Tesso DW. Determinants of long-acting and permanent contraceptive methods utilization among married women of reproductive age in Western Ethiopia: a cross-sectional study. Contraception. 2015:92(4):402.

34. Zenebe $C B$, et al. Factors associated with utilization of long-acting and permanent contraceptive methods among women who have decided not to have more children in Gondar city. BMC Womens Health. 2017;17(1):75.

35. White JS, Speizer IS. Can family planning outreach bridge the urban-rural divide in Zambia? BMC Health Serv Res. 2007;7(143).

36. Weidert, K., Prata, N., Bell, S., Nieto-Andrade, B., Carvahlo, A., \& Neves, I, Varying family planning strategies across age categories: differences in factors associated with current modern contraceptive use among youth and adult women in Luanda, Angola, Open Access Journal Of Contraception, 2016. 1.

\section{Publisher's Note}

Springer Nature remains neutral with regard to jurisdictional claims in published maps and institutional affiliations.

Ready to submit your research? Choose BMC and benefit from:

- fast, convenient online submission

- thorough peer review by experienced researchers in your field

- rapid publication on acceptance

- support for research data, including large and complex data types

- gold Open Access which fosters wider collaboration and increased citations

- maximum visibility for your research: over $100 \mathrm{M}$ website views per year

At BMC, research is always in progress.

Learn more biomedcentral.com/submissions 